Article

\title{
Tartrate-Based Electrolyte for Electrodeposition of Fe-Sn Alloys
}

\author{
Simona Mrkonjić Zajkoska ${ }^{1,2, *}$, Edmund Dobročka ${ }^{3}$, Selma Hansal ${ }^{1}$, Rudolf Mann ${ }^{1}$, \\ Wolfgang E. G. Hansal ${ }^{1}$ and Wolfgang Kautek ${ }^{2}$ D \\ 1 Hirtenberger Engineered Surfaces GmbH, Leobersdorfer Strasse 31-33, A-2552 Hirtenberg, Austria; \\ selma.hansal@hirtenberger.com (S.H.); rudolf.mann@hirtenberger.com (R.M.); \\ wolfgang.hansal@hirtenberger.com (W.E.G.H.) \\ 2 Department of Physical Chemistry, University of Vienna, Währinger Strasse 42, A-1090 Vienna, Austria; \\ wolfgang.kautek@univie.ac.at \\ 3 Institute of Electrical Engineering, Slovak Academy of Sciences, Dúbravská cesta 9, \\ 84104 Bratislava, Slovak Republic; elekdobr@savba.sk \\ * Correspondence: simona.zajkoska@hirtenberger.com
}

Received: 11 April 2019; Accepted: 7 May 2019; Published: 10 May 2019

\begin{abstract}
Magnetic properties of the sustainable Fe-Sn alloys are already known. However, there is lack of information in the field of Fe-Sn electrodeposition. In the present study, a novel Fe(III)-Sn(II) electrolyte with tartaric acid as a single complexing agent is introduced. The influence of the $\mathrm{pH}$ and the current density on the structural properties of the Fe-Sn deposit was studied. The stability of the electrolytes as a main attribute of sustainability was tested. The ferromagnetic phases $\mathrm{Fe}_{5} \mathrm{Sn}_{3}$ and $\mathrm{Fe}_{3} \mathrm{Sn}$ were electrodeposited for the first time, and it was found that the mechanism of the $\mathrm{Fe}-\mathrm{Sn}$ deposition changes from normal to anomalous at a $\mathrm{pH}$ value 3.0 and a current density of approximately $30 \mathrm{~mA} / \mathrm{cm}^{2}$. A possible reason for the anomalous deposition of Fe-Sn is the formation of Fe-hydroxides on the cathode surface. Two electrolyte stability windows exist: The first stability window is around a $\mathrm{pH}$ value of 1.8 where bimetallic Fe-Sn tartrate complexes were formed, and second one is around a $\mathrm{pH}$ value of 3.5 where most of the Sn ions were present in the form of $\left[\mathrm{Sn}(\operatorname{tart})_{2}\right]^{2-}$ and Fe in the form of $[\mathrm{Fe}(\operatorname{tart})]^{+}$complexes.
\end{abstract}

Keywords: electrodeposition; iron-tin alloys; tartaric acid; anomalous deposition; intermetallic; electrolyte stability

\section{Introduction}

The $\mathrm{Fe}-\mathrm{Sn}$ alloys recently gained attention due to their potential for various magnetic applications [1,2]. Among the five intermetallic phases $\mathrm{FeSn}_{2}, \mathrm{FeSn}, \mathrm{Fe}_{3} \mathrm{Sn}_{2}, \mathrm{Fe}_{5} \mathrm{Sn}_{3}$, and $\mathrm{Fe}_{3} \mathrm{Sn}$ present in the $\mathrm{Fe}-\mathrm{Sn}$ phase diagram, the iron-rich phases are of particular interest due to their ferromagnetic properties [3]. The tin-rich phases $\mathrm{FeSn}_{2}$ and $\mathrm{FeSn}$ are antiferromagnetic [3]. Various Fe-Sn alloys have been prepared by mechanical milling [4,5], magnetron sputtering [6,7], or by mechanical alloying [8]. The available literature in the field of Fe-Sn electrodeposition is very limited. Yamamoto et al. [9] detected the $\mathrm{FeSn}_{2}$ phase after annealing samples of electrodeposited Sn on Fe substrate. Chisholm et al. [10] have studied the electrodeposition of Fe-Sn from a gluconate based electrolyte. The authors have studied the influence of electrolyte $\mathrm{pH}$, temperature, current density, and $S n: F e$ ion ratio in the electrolyte. It was found out that in all studied cases, the electrodeposition of Fe-Sn from an Fe(II)-Sn(II) gluconate-based electrolyte exhibits normal co-deposition. Tin-rich deposits with amorphous $\mathrm{Sn}-\mathrm{Fe}$ and antiferromagnetic $\mathrm{FeSn}_{2}$ phases were deposited in this way.

Electrolyte stability is one of the main issues for sustainable electrodeposition. The standard reduction potential of oxygen $\left(E^{0}=1.229 \mathrm{~V}\right)$ is more positive than the one from $\mathrm{Fe}^{3+}$ to $\mathrm{Fe}^{2+}\left(E^{0}=0.771 \mathrm{~V}\right)$. 
Therefore, the spontaneous oxidation of $\mathrm{Fe}^{2+}$ to $\mathrm{Fe}^{3+}$ will occur due to the presence of dissolved oxygen in the electrolyte. As a result, the cathodic current efficiency will decrease. Usage of the reducing agents can inhibit, but not eliminate, the oxidation of $\mathrm{Fe}^{2+}$ to $\mathrm{Fe}^{3+}$. Moreover, the kinetics of the reduction depends on the electrolyte $\mathrm{pH}$ [11]. Another option to avoid the problem of Fe oxidation is the use of Fe(III) salts for electrodeposition.

The aim of this is study is the electrodeposition of Fe-Sn alloys from a novel Fe(III)-Sn(II) electrolyte with tartaric acid as single complexing agent. The influence of the electrolyte $\mathrm{pH}$ and deposition current density on the stoichiometry and structure of the deposit was studied. The potentiodynamic measurements and electrolyte speciation distributions were used to explain the mechanism of the Fe-Sn electrodeposition. The stability of the electrolyte was tested, and the results were compared with the electrolyte speciation distribution.

\section{Materials and Methods}

The mechanism of the Fe-Sn electrodeposition was studied in electrolytes containing: $0.11 \mathrm{M}$ $\mathrm{FeCl}_{3}$ (VWR Chemicals, Leuven, Belgium), $0.11 \mathrm{M} \mathrm{SnCl}_{2}$ (abcr GmbH, Karlsruhe, Germany), $0.44 \mathrm{M}$ $\mathrm{C}_{4} \mathrm{H}_{4} \mathrm{O}_{6}$ (Alfa Aesar, Karlsruhe, Germany), and $0.45 \mathrm{M}\left(\mathrm{NH}_{4}\right)_{2} \mathrm{SO}_{4}$ (VWR Chemicals, Leuven, Belgium). Supporting electrolytes were prepared by dissolving $0.45 \mathrm{M}\left(\mathrm{NH}_{4}\right)_{2} \mathrm{SO}_{4}$ and $0.44 \mathrm{M} \mathrm{C}_{4} \mathrm{H}_{4} \mathrm{O}_{6}$ in DI water. Single metal electrolytes were containing $0.11 \mathrm{M}$ of either Fe or Sn. The $\mathrm{pH}$ of the electrolytes was changed in the range from 1.8 to 4.5 and a solution of $30 \% \mathrm{NaOH}$ was used to adjust the $\mathrm{pH}$. The temperature of the electrolytes was kept at $60{ }^{\circ} \mathrm{C}$ with a hot plate.

Calculations of the metal speciation were performed in Visual MINTEQ 3.1 [12]. The redox reaction of $\mathrm{Fe}(\mathrm{III})-\mathrm{Sn}(\mathrm{II})$ was not considered in the chemical equilibrium modeling. Consequently, Hyperquad Simulation and Speciation (HySS) software (HySS2009) [13] was used for the calculation of species' concentration and visualization.

Electrochemical measurements were carried out in an open glass beaker using a three-electrode setup with the $\mathrm{Ag} / \mathrm{AgCl}$ (sat. $\mathrm{KCl}$ ) used as a reference and $\mathrm{Pt}$ as a counter electrode. In the manuscript, all potential values are vs. standard hydrogen electrode (SHE) as a reference. Potentiodynamic measurements were performed using an IPS PGU 20V-2A-E potentiostat (IPS Elektroniklabor GmbH \& Co. KG, Münster, Germany). For the cyclic voltammograms (CV), a CHI 101 stationary gold disc electrode $(\Phi=2 \mathrm{~mm})$ was used as working electrode. Before every experiment, the gold cathode was wet polished to a mirror bright finish with 4000 grid silicon paper and rinsed with deionized water. Cyclic voltammograms were recorded at a scan rate of $50 \mathrm{mV} / \mathrm{s}$ from the Open Circuit Potential (OCP) towards cathodic direction up to $-1303 \mathrm{mV}$ vs. SHE and during the reverse scan up to $+697 \mathrm{mV}$ vs. SHE.

The estimation of the deposition potential of Fe in the tartrate electrolyte was carried out in an electrolyte containing $0.11 \mathrm{M}$ of $\mathrm{Fe}$ as a single electroactive species. A series of $\mathrm{CVs}$ with a variation of the cathodic reverse potential from -703 to $-1303 \mathrm{mV}$ vs. SHE with the step of $-100 \mathrm{mV}$ and the scan rate of $50 \mathrm{mV} / \mathrm{s}$ was recorded. The appearance of the anodic dissolution peak of Fe indicated the position of the Fe reduction potential.

Galvanostatic Fe-Sn deposits were obtained from Hull cell experiments, which were carried out in a standard $267 \mathrm{~mL}$ cell (Kocour, Chicago, IL, USA) [14]. As a substrate brass (Kocour, 69 at \% Cu, 31 at $\% \mathrm{Zn}$ ) was used. The surface of the working electrode was activated with $10 \% \mathrm{H}_{2} \mathrm{SO}_{4}$ for $30 \mathrm{~s}$ before the Hull cell experiments. A total constant current of $2000 \mathrm{~mA}$ was applied for $7 \mathrm{~min}$ on a brass substrate. The current density on the Hull cell substrate varied from 1 to $80 \mathrm{~mA} / \mathrm{cm}^{2}$. In this way, it has been guaranteed that the deposition takes place above the deposition potential across the whole testing plate. Structural characterization of the Fe-Sn deposits was performed on the $1 \times 1 \mathrm{~cm}^{2}$ samples cut from the Hull cell electrode along the current density of 20 and $80 \mathrm{~mA} / \mathrm{cm}^{2}$.

The surface topography and the deposit stoichiometry were analyzed with the scanning electron microscope (SEM) Hitachi S-4800 (Hitachi, Tokyo, Japan) equipped with an energy dispersive X-ray detector (EDX). XRD analysis has been carried out using diffractometer Bruker D8 DISCOVER (Bruker, 
Billica, MA, USA) equipped with an X-ray tube with a rotating $\mathrm{Cu}$ anode operating at $12 \mathrm{~kW}$. All measurements were performed in parallel beam geometry with a parabolic Goebel mirror in the primary beam. A LiF monochromator was inserted into diffracted beam in order to suppress the fluorescent radiation. The X-ray diffraction patterns were recorded in a grazing incidence set-up with the angle of incidence $\alpha=6^{\circ}$ in the angular range of $20^{\circ}-100^{\circ}$ with step size $0.02^{\circ}$ and measuring time of $1 \mathrm{~s}$ per step. The lattice parameters and crystallite size, in terms of volume weighted column-length, were determined by the Pawley method using the software TOPAS 3.0 from Bruker-AXS. The approximate mass fractions of the detected phases were determined by the Rietveld method using the same software.

In order to revise electrolyte stability, $250 \mathrm{~mL}$ of each electrolyte was prepared in an open glass beaker and kept on a hot plate at $60{ }^{\circ} \mathrm{C}$ while stirring with $250 \mathrm{rpm}$. If precipitates developed, they were isolated after approximately $3 \mathrm{~h}$ of ageing and they were dried in air.

\section{Results and Discussions}

\subsection{Electrolyte Speciation}

In aqueous solutions, both stannous and ferric ions can be present as free ions as well as in the form of complexes with tartrate, chloride, and sulphate. Based on the chemical equilibrium, the ferric-stannous redox reaction was not considered. The calculation of the metal speciation was performed with the Software Visual MINDTEQ 3.1 [12]. The pH-dependent speciation of the electrolytes was calculated by the HySS software [13]. The results are depicted in Figure 1. In the acidic region of mixed Fe-Sn electrolytes stannous ions are present either as free ions, charged or neutral chloride complexes, or as neutral Sn-tartrate complexes. In the $\mathrm{pH}$ region from 3.0 to 8.0, all tin molecules are present in the stable form of $\left[\mathrm{Sn}(\operatorname{tartr})_{2}\right]^{2-}$ complexes. In the weak alkaline region, tin(II) hydroxides are observed (Figure 1c). Ferric ions in the mixed Fe-Sn acidic electrolytes are present as free ions or charged chloride and sulfate complexes. In the $\mathrm{pH}$ range from 3.0 to 5.0, all ferric molecules are present in the stable complex $[\text { Fetart }]^{+}$. Soluble $\left[\mathrm{Fe}(\mathrm{OH})_{2}\right]^{+}$starts to appear around $\mathrm{pH} 5.0$, while insoluble hydroxides $\mathrm{Fe}(\mathrm{OH})_{3}$ and $\left[\mathrm{Fe}(\mathrm{OH})_{4}\right]^{-}$are formed in the weak alkaline region $(\mathrm{pH} \sim 8.0)$ (Figure 1d). Considering the $\mathrm{pH}$ dependence of electrolyte speciation, the $\mathrm{pH}$ range for stable ferric-stannous electrolytes was assumed to be between the values of 3.0 and 5.0.

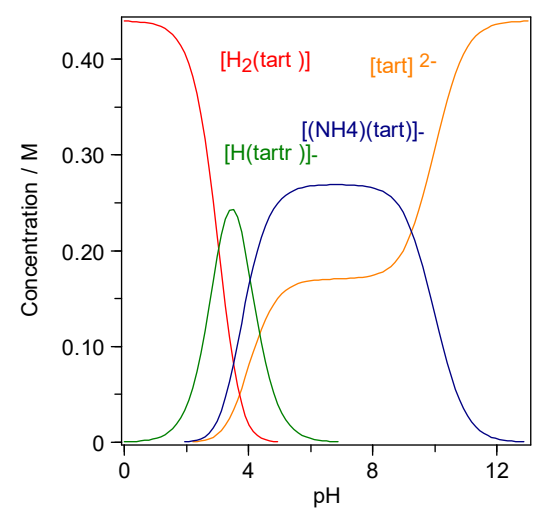

(a)

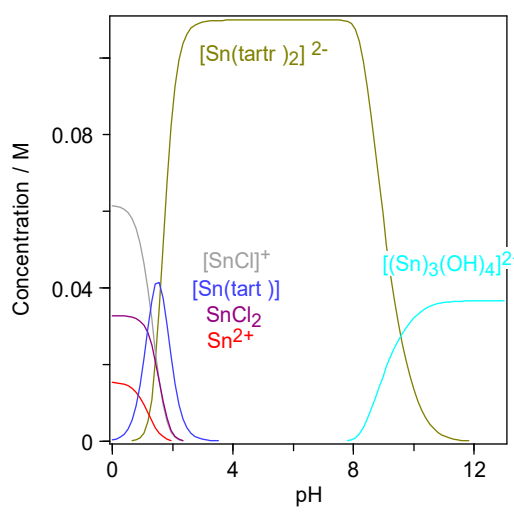

(b)

Figure 1. Cont. 


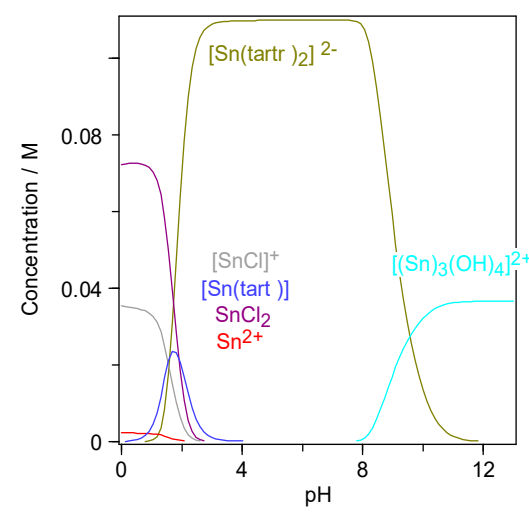

(c)

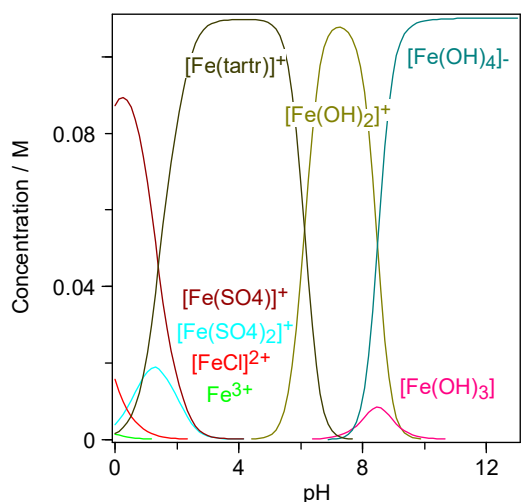

(d)

Figure 1. Calculated electrolyte speciation from the $\mathrm{pH}$ value 0 to 13: (a) Supporting electrolyte, without any metal ions, (b) Sn (0.11 M) single metal electrolyte, (c) Sn(II) species in the mixed Fe(III)-Sn(II) electrolyte, and (d) Fe(III) species in the mixed Fe(III)-Sn(II) electrolyte.

\subsection{Electrochemical Characterization}

As a first step, CVs in the supporting electrolyte, without any metal ions, at different $\mathrm{pH}$ values were measured (Figure 2). For all measured CVs, reduction peaks attributed to hydrogen reduction were observed in the cathodic sweeps, independent of the $\mathrm{pH}$ values of the electrolytes. At higher $\mathrm{pH}$, with the beginning at a $\mathrm{pH}$ value of 3.0, a reduction peak around $-800 \mathrm{mV}$ started to appear. This peak, reaching its maximum intensity at the $\mathrm{pH}$ value of 3.5, was not related to any oxidation peak (Figure 2). According to the speciation of the supporting electrolyte (Figure 1a) within the $\mathrm{pH}$ range of 2.0 to 4.0 the most of the tartrate ligands were present in the form of $\left[\mathrm{H}_{2}(\operatorname{tart})\right]$ and $[\mathrm{H}(\operatorname{tart})]^{-}$. Predominant species around $\mathrm{pH}$ value of $3.5 \mathrm{was}[\mathrm{H}(\operatorname{tart})]^{-}$. Therefore, the cathodic peak, observed around $-800 \mathrm{mV}$ (Figure 2), could be related to the reduction of hydrogen ions from the $[\mathrm{H}(\operatorname{tart})]^{-}$ion [15]. During the anodic sweep of the CVs, no oxidation peaks were detected (Figure 2). Therefore, it can be assumed that no oxidation of tartaric acid or its anions occurred.

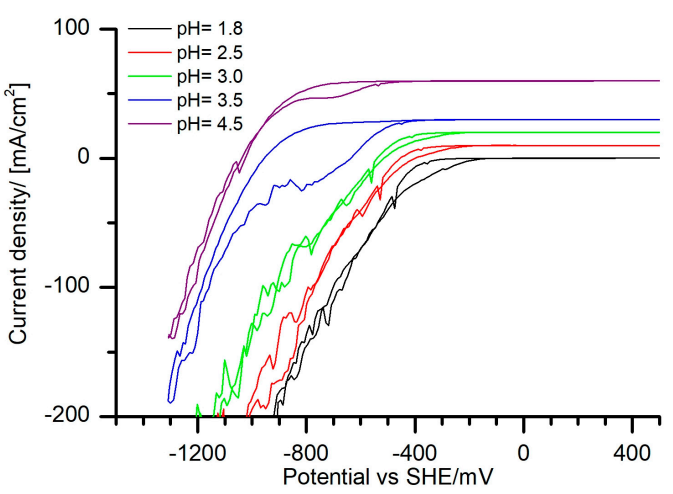

Figure 2. Cyclic voltammograms (CVs) of the supporting electrolyte recorded at different $\mathrm{pH}$ values of the electrolyte (offset $10 \mathrm{~mA} / \mathrm{cm}^{2}$ ) with the scan rate of $50 \mathrm{mV} / \mathrm{s}$.

Results of the cyclic voltammograms (CVs) in the Fe(III)-Sn(II) electrolyte for various $\mathrm{pH}$ values are depicted in the Figure 3. In the cathodic branch, two reduction peaks (I, II) and three crossovers (A, $\mathrm{B}, \mathrm{C})$ were detected. The peak Nr. I was assigned to the Sn reduction and it is strongly $\mathrm{pH}$ dependent. By increasing the $\mathrm{pH}$, the $\mathrm{Sn}$ reduction peak was shifted towards more negative potentials. Such a shift was also observed by Lingane [16] in the Sn(II)-tartrate electrolytes. The author explained it with the fundamental difference in the composition of $\mathrm{Sn}(\mathrm{II})$-tartrate complexes in the acidic and alkaline media. Moreover, according to the polarographic measurements, the presence of ferric ions in the tartrate electrolyte containing a 1:1 ratio of $\mathrm{Sn}(\mathrm{II})$ and $\mathrm{Fe}(\mathrm{III})$ did not change the reduction potential 
of Sn(II) [17]. According to the electrolyte speciation (Figure 1c), in the case of Fe(III)-Sn(II) tartrate electrolyte, the character of the stannous complexes changed from the [ $\mathrm{SnCl}]^{-},[\mathrm{SnCl}]$, and [Sn(tart)] in the acidic media through $[\mathrm{Sn}(\operatorname{tart})]^{+}$in weak acidic-neutral towards $\left[\mathrm{Sn}_{3}(\mathrm{OH})_{4}\right]^{2+}$ in the alkaline media. The concentration of the $\left[\mathrm{Sn}(\operatorname{tart})_{2}\right]^{2-}$ complexes within the $\mathrm{pH}$ values of 3.0 and 7.0 is almost constant. Moreover, the $\mathrm{pK}_{\mathrm{s} 2}$ value of tartaric acid is 4.34 [18]. Due to the dissociation of $[\mathrm{H}(\operatorname{tart})]^{-}$, the change of concentration of [tart $]^{2-}$ reaches a maximum around this $\mathrm{pH}$ value (Figure $1 \mathrm{a}$ ). Therefore, it is reasonable to assume that the shift of the $\mathrm{Sn}$ reduction potential in this $\mathrm{pH}$ region is due to the increased stability of the $\left[\mathrm{Sn}(\operatorname{tart})_{2}\right]^{2-}$ complex.

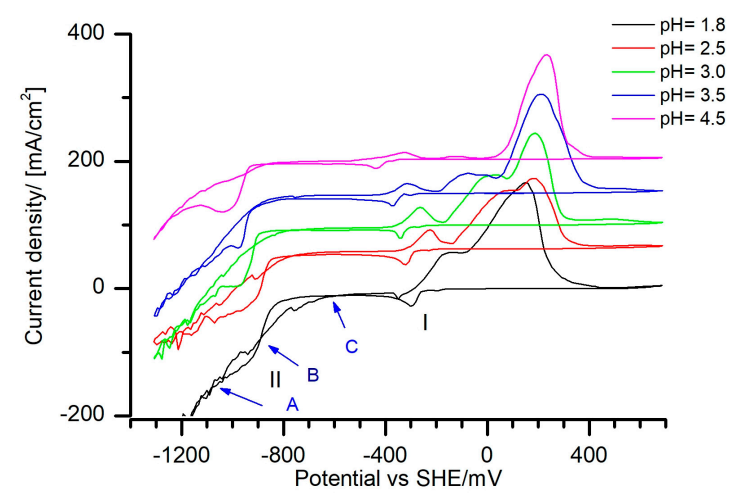

Figure 3. CVs in the Fe(III)-Sn(II) electrolytes (both Fe and $\mathrm{Sn} 0.11 \mathrm{M}$ ) recorded at different $\mathrm{pH}$ values. The cathode was polarized first until $-1303 \mathrm{mV}$ and then until $-703 \mathrm{mV}$ vs. standard hydrogen electrode (SHE) with the scan rate of $50 \mathrm{mV} / \mathrm{s}$.

A decrease of the $\mathrm{Sn}$ reduction peak intensity as a function of a $\mathrm{pH}$ was detected (Figure 3). A possible explanation could be the suppression of Sn reduction due to the presence of ferric ions. A similar effect was observed in the Ni-Fe anomalous co-deposition [19] where the electrodeposition of the more noble $\mathrm{Ni}$ was suppressed by the presence of Fe at relatively low overpotentials. The suppression of Ni began when Fe-hydroxides where formed on the cathode surfaces. According to the $\mathrm{Fe}(\mathrm{III})-\mathrm{Sn}$ (II) electrolyte speciation, soluble Fe-hydroxides are starting to form around $\mathrm{pH}$ value of 4.0 (Figure 1d). Due to the local rise of the $\mathrm{pH}$ on the cathode surface, Fe-hydroxides might also be present in electrolytes with a bulk pH below 4.0. This finding indicates, that with the increase of the electrolyte $\mathrm{pH}, \mathrm{Fe}-\mathrm{Sn}$ might undergo anomalous deposition.

The Sn reduction peak was followed by the diffusion limiting current density plateau in all of the studied electrolytes (Figure 3). According to the Nernst equation [20], the standard hydrogen evolution potential $\left(E^{0}\right)$ is shifted from -104 to $-261 \mathrm{mV}$ for $\mathrm{pH}$ values of 1.8 and 4.5 respectively. This indicates that hydrogen evolution (HER) is present as a side reaction over the whole deposition potential range [21]. The presence of various additives and complexing agents in the electrolyte can shift the HER to higher overpotentials than $E^{0}$. In the case of the Fe(III)-Sn(II) electrolyte used, the HER potential was shifted to values of $-900 \mathrm{mV}$ and below, and a linear increase of the current density was observed (Figure 3).

The reduction peak Nr. II was shifted from -890 towards $-962 \mathrm{mV}$ for the $\mathrm{pH}$ values of 1.8 and 4.5 , respectively. In the vicinity of peak Nr. II two crossovers (A, B) of cathodic and anodic scans were observed (Figure 3). Generally, for single metal electrodeposition, the presence of a crossover indicates the existence of a nucleation process. The first crossover corresponds to the nucleation overpotential, since the potential of metal deposition on itself is more positive than for the metal deposition on a foreign substrate. The second crossover corresponds to the equilibrium potential of Metal/Metal ${ }^{n+}$ couple [22]. On the other hand, the reduction peak around $-800 \mathrm{mV}$ in the supporting electrolyte was assigned to the reduction of the hydrogen from the $[\mathrm{H}(\operatorname{tart})]^{-}$and $\left[\mathrm{H}_{2}(\operatorname{tart})\right]$ species (Figures $1 \mathrm{a}$ and 2). For these reasons, the cathodic peak Nr. II in the Fe(III)-Sn(II) electrolyte (Figure 3) might 
be related either to the reduction of some metal phase or to hydrogen reduction from $[\mathrm{H}(\operatorname{tart})]^{-}$and $\left[\mathrm{H}_{2}\right.$ (tart) $]$ complexes.

The anodic sweeps of the CVs exhibited a rather complex behavior. Two different current peaks were detected at $\mathrm{pH}$ values of 1.8 and 2.5. Starting from the $\mathrm{pH}$ value of 3.0, three different current peaks appeared (Figure 3). Considering the observed $\mathrm{pH}$ influence on the $\mathrm{Sn}$ reduction potential and the increased number of the stripping peaks, it was assumed that starting from the $\mathrm{pH}$ value of 3.0 additional Fe-Sn metal phases could be deposited.

In order to relate the peak Nr. II (Figure 3) with hydrogen or with metal phase reduction, the iron deposition potential was studied. For this purpose, CVs with different cathodic reverse potentials in the single metal Fe(III)-tartrate electrolyte were measured (Figure 4). An anodic dissolution peak was first observed when the electrode was polarized cathodically up to $-903 \mathrm{mV}$. On the other hand, no dissolution peak was observed when the electrode was polarized to $-803 \mathrm{mV}$. Hence, the position of Fe deposition potential at the $\mathrm{pH}$ value of 1.8 was located between -803 and $-903 \mathrm{mV}$. This finding confirms that the cathodic peak Nr. II in the mixed Fe-Sn electrolyte (Figure 3) could be also related to the deposition of Fe or an Fe-Sn phase.

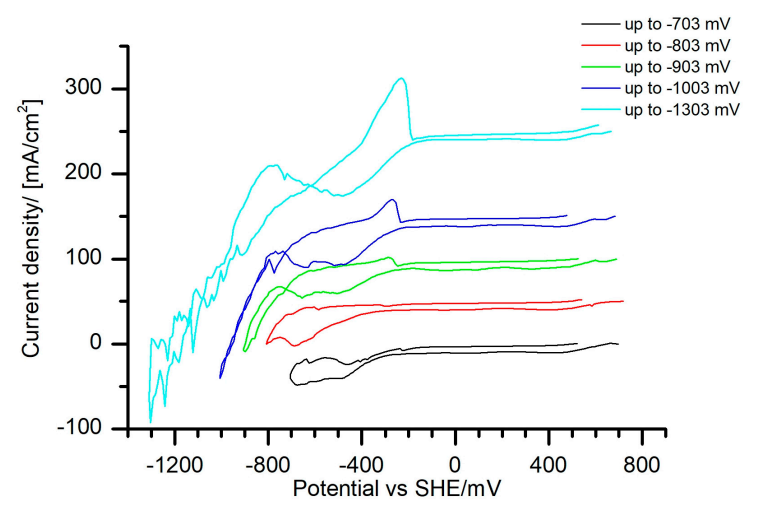

Figure 4. $\mathrm{CVs}$ in single metal $\mathrm{Fe}(\mathrm{III})$-tartrate electrolyte recorded with the scan rate of $50 \mathrm{mV} / \mathrm{s}$ at the $\mathrm{pH}$ value of 1.8. The cathodic reverse potential was varied from -703 to $-1303 \mathrm{mV}$ vs. SHE. The position of Fe reduction potential was estimated according to the appearance of the anodic dissolution peak.

\subsection{Structural Characterization}

In order to study the Fe-Sn electrodeposition in the current density range from 1 to $80 \mathrm{~mA} / \mathrm{cm}^{2}$, Hull cells were used. SEM topography images and deposit stoichiometries are listed in Table 1. The surface of the Hull cell cathodes, deposited from electrolytes in the $\mathrm{pH}$ range of 1.8 to 3.0, was covered with dendrites over the whole current density range. At higher $\mathrm{pH}$ values, 3.5 and 4.5 , the character of the dendrites changed to powder (not shown). In order to analyze the compact layer below the dendrites and the powder, these were removed from the samples by a cotton pad with isopropanol. In all studied samples, a high amount of oxygen was observed (Table 1). The oxygen content varied from 48.7 to 21 at \% for the samples deposited at $\mathrm{pH}$ value 1.8 with $20 \mathrm{~mA} / \mathrm{cm}^{2}$ and the $\mathrm{pH}$ value of 4.5 with the current density of $80 \mathrm{~mA} / \mathrm{cm}^{2}$, respectively. Samples deposited at the $\mathrm{pH}$ value of $1.8 \mathrm{had}$ the highest surface roughness and therefore, also the biggest surface area. Additionally, no Fe or $\mathrm{Sn}$ hydroxides should be present at such an acidic pH (Figure 1c,d). Therefore, it could be assumed that the high oxygen content is a surface phenomenon dependent on the deposit surface roughness. From the EDX analyses, it is obvious that, with the increase of the electrolyte $\mathrm{pH}$, the amount of $\mathrm{Sn}$ in the deposit decreased. Iron-rich deposits were obtained with both $20 \mathrm{~mA} / \mathrm{cm}^{2}$ (pH values of 3.5 and 4.5) and $80 \mathrm{~mA} / \mathrm{cm}^{2}$ (pH range from 3.0 to 4.5 ) (Table 1). This observation agrees with the potentiodynamic results, in which suppression of the reduction of the more noble $\mathrm{Sn}$ with the increasing $\mathrm{pH}$ was detected (Figure 3). 
Table 1. SEM topography images and energy dispersive X-ray detector (EDX) stoichiometry results from Hull cells samples deposited with the approximate current densities of 20 and $80 \mathrm{~mA} / \mathrm{cm}^{2}$.

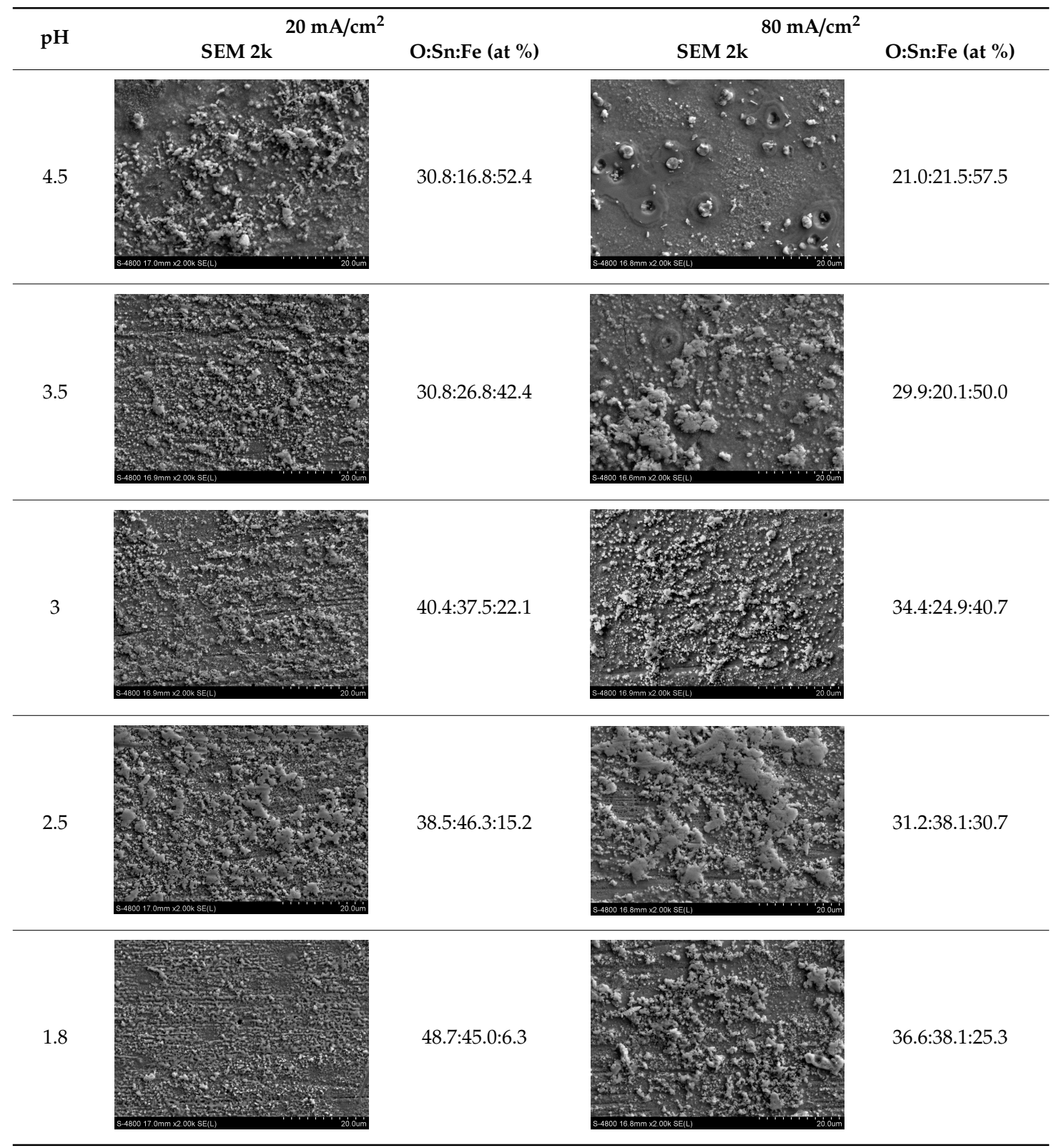

Anomalous co-deposition, enhanced deposition of the less noble metal, and suppression of the reduction of the more noble one, has been reported for various iron alloys [19,23-25]. A literature overview showed no report of an anomalous codeposition in the Fe-Sn system. The iron content, as a function of current density in the Hull cells, was studied (Figure 5). The assumptions, based on the $\mathrm{CVs}$ results (Figure 3), of the suppression of the Sn reduction and Fe-Sn anomalous co-deposition were confirmed. In the samples deposited at the $\mathrm{pH}$ value of 3.0, Fe-rich deposits were obtained starting with $30 \mathrm{~mA} / \mathrm{cm}^{2}$. In the case of the electrolyte with the $\mathrm{pH}$ value of 4.5 , Fe-rich deposits were obtained over the whole studied current density range. These findings indicate that anomalous deposition of Fe-Sn from tartrate electrolyte starts to appear at a current density of around $30 \mathrm{~mA} / \mathrm{cm}^{2}$ and a $\mathrm{pH}$ value of 3.0. Moreover, the $\mathrm{Fe}-\mathrm{Sn}$ anomalous deposition is a $\mathrm{pH}$ - and current density-dependent phenomenon. One of the possible explanations for the anomalous co-deposition is blocking of the cathode surface with hydroxides [19,21]. According to the species simulation (Figure 1c,d), Fe hydroxides starts to form from around the $\mathrm{pH}$ value of 4 and $\mathrm{Sn}$ hydroxides start to appear around the $\mathrm{pH}$ value of 8.0. 
Consequently, it can be assumed that the possible reason for the Fe-Sn anomalous co-deposition is the presence of Fe hydroxides on the cathode surface.

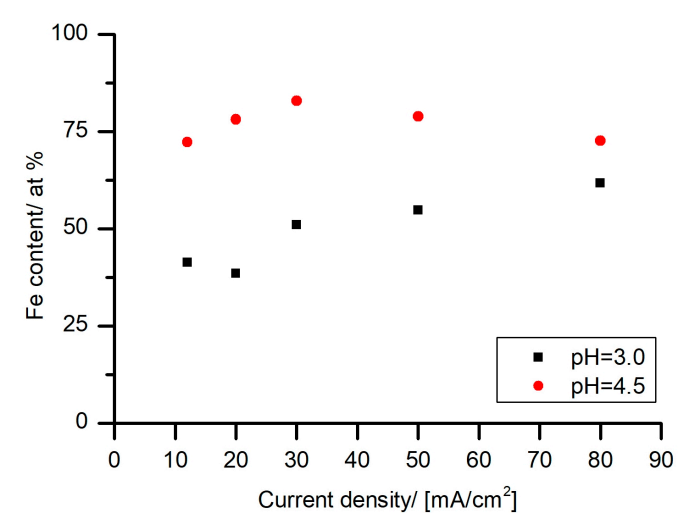

Figure 5. Change of the iron content in the deposits as a function of the current density. Samples were prepared from the $\mathrm{Fe}(\mathrm{III})-\mathrm{Sn}(\mathrm{II})$ electrolytes with the $\mathrm{pH}$ values of 3.5 and 4.5. Iron-rich deposits were prepared starting from the current density $30 \mathrm{~mA} / \mathrm{cm}^{2}$ at the $\mathrm{pH}=3.5$.

The layers on the Hull cell samples deposited with 20 and $80 \mathrm{~mA} / \mathrm{cm}^{2}$ at different $\mathrm{pH}$ values were characterized by XRD diffraction. The XRD-diffraction patterns were recorded in the angular range of $20^{\circ}-100^{\circ}$. For the phase identification, the most relevant was the $2 \theta$ range $27^{\circ}-47^{\circ}$ (Figure 6). Three intermetallic phases, $\mathrm{FeSn}_{2}$ (PDF-04-006-5524), $\mathrm{Fe}_{5} \mathrm{Sn}_{3}$ (PDF-03-065-7052), $\mathrm{Fe}_{3} \mathrm{Sn}$ (PDF-03-065-3524), and Sn (PDF-04-008-4977) were observed in all of the electrodeposited samples, independent of current density and the electrolyte $\mathrm{pH}$. Additionally, $\alpha$-Fe (PDF-01-089-4186) was detected at the samples deposited with $20 \mathrm{~mA} / \mathrm{cm}^{2}$ with the $\mathrm{pH}$ values between 3.0 and 4.5 as well as with $80 \mathrm{~mA} / \mathrm{cm}^{2}$ with the $\mathrm{pH}$ values of 3.0 and 3.5. A decrease in the intensity and broadening of the peaks $\left(30.7^{\circ}, 32^{\circ}\right.$ and $45^{\circ}$ ) related to the diffraction of $\beta$-Sn was observed with the increasing electrolyte $\mathrm{pH}$ for both studied current densities (Figure 6). The same tendency was observed for the $\mathrm{Fe}_{5} \mathrm{Sn}_{3}$ diffraction peak at $30^{\circ}$ for the samples deposited with $20 \mathrm{~mA} / \mathrm{cm}^{2}$. These findings indicate that with an increase of the $\mathrm{pH}$ of the electrolyte, the amount of the electrodeposited $\beta-\mathrm{Sn}$ and $\mathrm{Fe}_{5} \mathrm{Sn}_{3}$ decreased and the crystallite size got smaller. The detected Fe-rich intermetallic phases $\mathrm{Fe}_{5} \mathrm{Sn}_{3}$ and $\mathrm{Fe}_{3} \mathrm{Sn}$ have hexagonal structure $\left(\mathrm{P}_{3} / \mathrm{mmc}\right)$ and exhibit ferromagnetic properties $[2,3]$. In the thermodynamic Fe-Sn phase diagram, both appear at temperatures above $1000 \mathrm{~K}$ [3]. Experimentally, they were prepared by DC-magnetron sputtering [6] and solid state reaction [2,3]. The available literature on electrodeposition in the Fe-Sn system showed no results for the preparation of $\mathrm{Fe}_{5} \mathrm{Sn}_{3}$ and $\mathrm{Fe}_{3} \mathrm{Sn}[10,26,27]$.

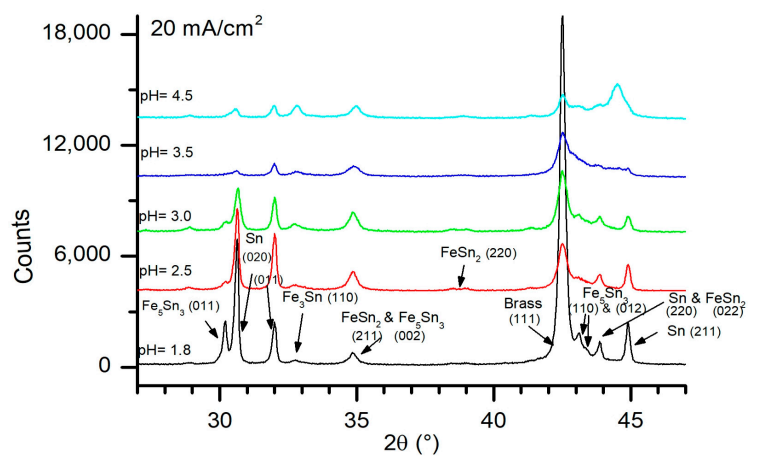

(a)

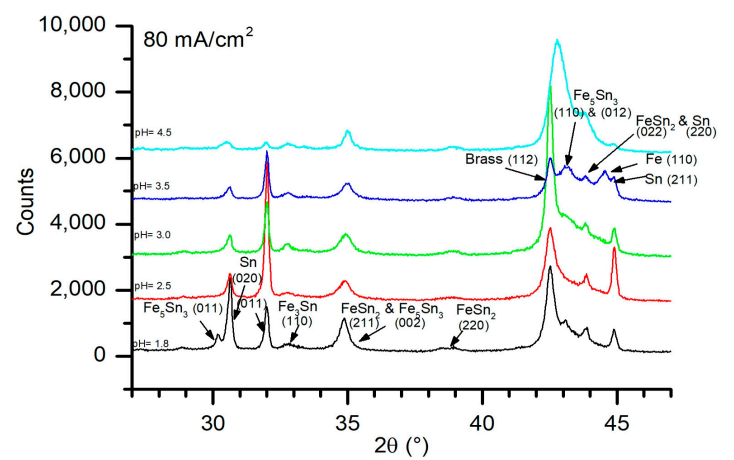

(b)

Figure 6. The most relevant part of the XRD diffraction pattern $\left(2 \theta: 27-47^{\circ}\right)$ for the phase identification. Samples were deposited from the Fe(III)-Sn(II) electrolytes (both Fe and Sn $0.11 \mathrm{M}$ ) at different $\mathrm{pH}$ values with the current density of: (a) $20 \mathrm{~mA} / \mathrm{cm}^{2}$, (b) $80 \mathrm{~mA} / \mathrm{cm}^{2}$. 
The Rietveld method was applied to the recorded XRD-diffraction patterns in order to quantify the amount of detected metal phases. The results, together with the calculated size of the crystallites ( $L$-vol), are listed in the Table 2. The recorded diffraction patterns were complex and with overlapping diffraction maxima (Figure 6). Hence, in the calculated values of the mass fractions and crystallite sizes, a significant error might occur. These values are marked with an asterisk in Table 2. Generally, based on the calculated values, several conclusions could be made. The results of the crystallite size and mass fraction calculations (Table 2) confirmed the assumptions based on the diffractograms observation (Figure 6). By increasing the $\mathrm{pH}$ of the electrolyte at both current densities, the amount of the electrodeposited $\beta$-Sn, and its crystallite size decreased. The same tendency was observed in the case of the $\mathrm{Fe}_{5} \mathrm{Sn}_{3}$ phase deposited with a current density of $20 \mathrm{~mA} / \mathrm{cm}^{2}$. In contrast, the amount of $\alpha-\mathrm{Fe}$, electrodeposited with a current density of $20 \mathrm{~mA} / \mathrm{cm}^{2}$, increased as a function of the electrolyte $\mathrm{pH}$. It also seems that the iron-rich phase $\mathrm{Fe}_{5} \mathrm{Sn}_{3}$ is preferentially deposited with a current density of $20 \mathrm{~mA} / \mathrm{cm}^{2}$. On the other hand, the tin-rich phase $\mathrm{FeSn}_{2}$ is preferentially deposited with a current density of $80 \mathrm{~mA} / \mathrm{cm}^{2}$. The obtained results (Table 2) also suggest that the amount of $\mathrm{Fe}_{3} \mathrm{Sn}$ is not depending on the electrolyte $\mathrm{pH}$ nor on the current density.

Table 2. Comparison of the mass fractions and crystallite sizes of the detected metallic phases of the deposited samples. Mass fractions were calculated with the use of the Rietveld method and the crystallite sizes were determined by the Pawley method by volume weighted column length.

\begin{tabular}{|c|c|c|c|c|c|c|c|c|c|c|c|}
\hline \multirow[b]{2}{*}{$\mathrm{pH}$} & \multirow[b]{2}{*}{$J\left(\mathrm{~mA} / \mathrm{cm}^{2}\right)$} & \multicolumn{2}{|c|}{ Sn } & \multicolumn{2}{|c|}{$\mathrm{FeSn}_{2}$} & \multicolumn{2}{|c|}{$\mathrm{Fe}_{5} \mathrm{Sn}_{3}$} & \multicolumn{2}{|c|}{$\mathrm{Fe}_{3} \mathrm{Sn}$} & \multicolumn{2}{|c|}{$\mathrm{Fe}$} \\
\hline & & wt $\%$ & $\begin{array}{l}\text { Cryst. } \\
\text { Size } \\
(\mathrm{nm})\end{array}$ & wt $\%$ & $\begin{array}{l}\text { Cryst. } \\
\text { Size } \\
(\mathrm{nm})\end{array}$ & wt $\%$ & $\begin{array}{l}\text { Cryst. } \\
\text { Size } \\
(\mathrm{nm})\end{array}$ & wt $\%$ & $\begin{array}{l}\text { Cryst. } \\
\text { Size } \\
(\mathrm{nm})\end{array}$ & wt $\%$ & $\begin{array}{l}\text { Cryst. } \\
\text { Size } \\
(\mathrm{nm})\end{array}$ \\
\hline 4.5 & & 9.76 & 43 & 19.7 & 14 & 3.27 & 7 & 0.44 & 23 & $66.8 *$ & $14^{*}$ \\
\hline 3.5 & & $11.4^{*}$ & $52 *$ & 26.6 * & $14 *$ & 11.8 * & $5.4^{*}$ & 0.11 & 14 & 50.15 & 12 \\
\hline 3.0 & 20 & 48.75 & 40 & 25.3 * & $15^{*}$ & 12.95 & 32 & 0.3 * & $19 *$ & $12.8 *$ & $10 *$ \\
\hline 2.5 & & 77.9 * & 80 * & 10.56 & 64 & 11.56 & 48 & - & - & - & - \\
\hline 1.8 & & 62.9 & 99 & 15.69 & 64 & 20.87 & 53 & $0.6^{*}$ & $19 *$ & - & - \\
\hline 4.5 & & 10.18 & 16 & 84.2 * & $13 *$ & $5.5^{*}$ & $9.5 *$ & 0.07 & 9 & - & - \\
\hline 3.5 & & 16.05 & 71 & $34.7^{*}$ & $10 *$ & $5.2 *$ & $7.3^{*}$ & 0.29 & 16 & 43.29 & 15 \\
\hline 3.0 & 80 & 19.41 & 38 & 33.3 * & 14 * & $3.6^{*}$ & $19 *$ & $0.5^{*}$ & $10 *$ & $43.2 *$ & $14 *$ \\
\hline 2.5 & & 67.82 & 73 & 29.4 * & $16^{*}$ & $2.1 *$ & $7 *$ & $0.7^{*}$ & 19 * & - & - \\
\hline 1.8 & & 37.6 & 65 & 52.1 * & $9 *$ & 10.2 & 34 & $0.1^{*}$ & 10 * & - & - \\
\hline
\end{tabular}

$*$ : data with higher uncertainty due to the overlapping diffraction maxima.

\subsection{Electrolyte Stability}

In the electrolyte speciation's simulation, several unstable or insoluble species such as [ $\mathrm{Sn}(\operatorname{tart})]$ or the iron hydroxides appeared (Figure 1). For the chemical equilibria calculation, the redox reaction of $\mathrm{Fe}(\mathrm{III})-\mathrm{Sn}(\mathrm{II})$ and the existence of bimetallic Fe-Sn-tartrate complexes were not considered. In order to revise the reliability of the species distribution, the stability of the electrolytes was studied. The stoichiometry of the precipitates was studied by EDX and the results are presented in Table 3 .

Table 3. Stoichiometry of the precipitates isolated after approximately $3 \mathrm{~h}$ of the electrolyte aging.

\begin{tabular}{cc}
\hline $\mathbf{p H}$ & $\begin{array}{c}\text { O:Sn:Fe } \\
\text { (at \%) }\end{array}$ \\
\hline 4.5 & $83.0: 1.8: 15.2$ \\
3.5 & $87.4: 11.3: 1.3$ \\
3 & $85.1: 14.1: 0.8$ \\
2.5 & electrolyte does not precipitate \\
1.8 & electrolyte does not precipitate \\
$1.8^{*}$ & 89.2:10.8:- \\
\hline \multicolumn{2}{r}{$*$ Sn single metal electrolyte $(0.11 \mathrm{M})}$.
\end{tabular}


The single metal Sn electrolyte $(0.11 \mathrm{M})$ at the $\mathrm{pH}$ value of 1.8 was rapidly precipitating. The XRD diffraction spectra on the Sn precipitate showed rather complex crystalline behavior (Figure 7). Although not all the diffraction peaks were successfully assigned, most of them (e.g., $13.8^{\circ}, 15.3^{\circ}, 18.2^{\circ}$, $18.9^{\circ}, 24.9^{\circ}$, etc.) were in good correlation with the powder diffractogram of [Sntartr] $]^{0}$ (PDF-00-001-0529). This finding agrees with the species distribution of the single metal Sn electrolyte (Figure $1 \mathrm{~b}$ ) where at the $\mathrm{pH}$ value of 1.8 approximately $0.04 \mathrm{M}$ of the $\mathrm{Sn}$ ions are present as neutral tartrate complex.

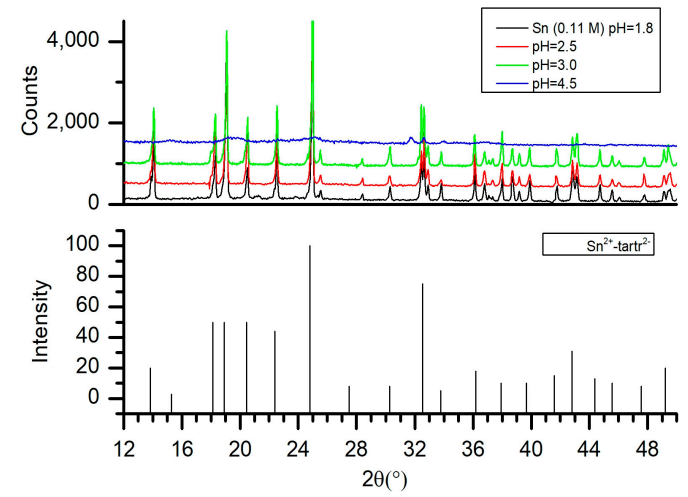

Figure 7. XRD diffraction patterns of precipitates isolated from the Sn- single metal and mixed $\mathrm{Fe}(\mathrm{III})-\mathrm{Sn}(\mathrm{II})$ electrolytes at the different $\mathrm{pH}$ values.

The $\mathrm{Sn}(\mathrm{II})$ electrolyte ( $\mathrm{pH}=1.8$ ) was stabilized with the addition of $\mathrm{FeCl}_{3}$. The mixed Fe(III)-Sn(II) electrolyte with the $\mathrm{pH}$ value of 1.8 was stored and observed for a week and during this time, no precipitates or change of color appeared (Table 3). Two explanations for the stabilization of the Sn(II) electrolyte by the $\mathrm{FeCl}_{3}$ are possible. The first one is based on the calculated species distribution (Figure $1 \mathrm{~b}-\mathrm{d}$ ). With the addition of the $0.11 \mathrm{M}$ of $\mathrm{FeCl}_{3}$ into the solution, the concentration of the $\mathrm{Cl}^{-}$ anions increased to $0.55 \mathrm{M}$. Consequently, the concentration of Sn-chloride complexes in the acidic region rose in respect to the concentration of [Sn(tart)] complexes which dropped to approximately half of its initial value $(0.02 \mathrm{M})$ (Figure $1 \mathrm{~b}, \mathrm{c})$ and therefore does not precipitate. The second possible explanation is based on the existence of bimetallic Sn-Fe-tartrate complexes [17]. In order to decide which explanation is correct, the concentration of $\mathrm{Cl}^{-}$anions in the single metal Sn electrolyte was adjusted to $0.55 \mathrm{M}$ by adding $\left(\mathrm{NH}_{4}\right) \mathrm{Cl}$ and the modified electrolyte was aged on a hot plate. After approximately half an hour, large amounts of a Sn-rich precipitate appeared. Based on this observation, we might conclude that single metal Sn electrolyte at the $\mathrm{pH}$ value of 1.8 was stabilized by the creation of bimetallic Fe-Sn-tartrate complexes.

As the $\mathrm{pH}$ of the mixed Fe(III)-Sn(II) electrolyte increased to the value of 2.5 and 3.0, crystalline [Sn(tart)] precipitates appeared again (Table 3, Figure 7). According to the species distribution (Figure 1c), at the $\mathrm{pH}$ value around 3.5, the concentration of the [Sn(tart)] drops down to $0 \mathrm{M}$. In the aged electrolyte at this $\mathrm{pH}$ value, only marginal amount of the precipitation appeared. After the filtration of the initial precipitate, the electrolyte appeared stable, without color change and further precipitation for more than a week. The amount of the filtered precipitate was not sufficient for a detailed analysis and the EDX and XRD analyses were not conclusive. For this reason, the electrolyte with the $\mathrm{pH}$ value of 3.5 was considered as stable.

In the electrolyte with a $\mathrm{pH}$ value of 4.5, Fe-rich amorphous precipitates were detected (Table 3 , Figure 7). This finding agrees with the speciation distribution, where Fe-hydroxides start to appear around the $\mathrm{pH}$ value of 4.0 (Figure 1d). During the electrodeposition process, the Fe hydroxides could be formed at bulk electrolyte $\mathrm{pH}$ values lower than 4.0 due to the local increase of the $\mathrm{pH}$ on the cathode surface. This observation agrees with the assumption that the Fe-Sn anomalous co-deposition is caused by the presence of Fe hydroxides on the cathode surface. 


\section{Conclusions}

A novel Fe(III)-Sn(II) tartrate electrolyte for electrodeposition of Fe-Sn was introduced. Structural characterization on Hull cell samples deposited with current densities of 20 and $80 \mathrm{~mA} / \mathrm{cm}^{2}$ in the $\mathrm{pH}$ range of 1.8 to 4.5 was performed. Electrolyte stability was investigated in the same $\mathrm{pH}$ range and the results were compared with the electrolyte speciation. The anomalous co-deposition of Fe-Sn was observed for the first time. It was found out that the mechanism of the Fe-Sn electrodeposition changed from regular to anomalous at a $\mathrm{pH}$ value of 3.0 and a current density of approximately $30 \mathrm{~mA} / \mathrm{cm}^{2}$. The possible explanation is that the $\mathrm{Sn}$ reduction was suppressed by the Fe-hydroxides which developed on the electrode surface at higher $\mathrm{pH}$ values.

The ferromagnetic $\mathrm{Fe}_{5} \mathrm{Sn}_{3}$ and $\mathrm{Fe}_{3} \mathrm{Sn}$ phases, which were electrodeposited for the first time, were detected in all samples. Besides them, pure $\mathrm{Sn}$ and $\mathrm{FeSn}_{2}$ were present in all studied samples. Additionally, $\alpha$-Fe was detected in the samples deposited with a current density of $20 \mathrm{~mA} / \mathrm{cm}^{2}$ with the $\mathrm{pH}$ values between 3.0 and 4.5 as well as with $80 \mathrm{~mA} / \mathrm{cm}^{2}$ with the $\mathrm{pH}$ values of 3.0 and 3.5 .

Two electrolyte stability windows were found. In the first one, with the $\mathrm{pH}$ value around 1.8, the electrolyte is stabilized by forming bimetallic Fe-Sn-tartrate complexes. Moreover, the optimum conditions for $\mathrm{Fe}_{5} \mathrm{Sn}_{3}$ electrodeposition were found to be at this $\mathrm{pH}$ value and the current density of $20 \mathrm{~mA} / \mathrm{cm}^{2}$. The second electrolyte stability window was found around the $\mathrm{pH}$ value of 3.5 where $\mathrm{Sn}$ was mostly present in the form of $\left[\mathrm{Sn}(\operatorname{tart})_{2}\right]^{2-}$ complexes and $\mathrm{Fe}$ in the form of $[\mathrm{Fe}(\operatorname{tart})]^{+}$complexes. At this $\mathrm{pH}$ value, Fe-Sn undergoes anomalous co-deposition over the whole current density range.

Author Contributions: Conceptualization, S.M.Z. and S.H.; Methodology, S.M.Z. and S.H.; Software, S.M.Z.; Validation, S.M.Z., E.D. and R.M.; Investigation, S.M.Z. and E.D.; Resources, W.E.G.H.; Writing-Original Draft Preparation, S.M.Z. and W.E.G.H.; Writing-Review \& Editing, S.M.Z., R.M. and W.E.G.H.; Visualization, S.M.Z.; Supervision, W.E.G.H. and W.K.; Project Administration, W.E.G.H.; Funding Acquisition, W.E.G.H.

Funding: This research was funded by HORIZON2020 SELECTA project (No. 642642).

Acknowledgments: Authors would like to thank Veronika Grman (HES) for conducting the SEM/EDX analyzes.

Conflicts of Interest: The authors declare no conflict of interest. The founding sponsors had no role in the design of the study; in the collection, analyses, or interpretation of data; in the writing of the manuscript, or in the decision to publish the results.

\section{References}

1. Dionisio, P.H.; Vasquez, A.; Hallouche, B.; Mosca, D.H., Jr.; Teixeira, S.R.; Schreiner, W.H.; Pasa, A.A. Structural and magnetic properties of iron-tin thin films. Thin Solid Films 1992, 217, 152-155. [CrossRef]

2. Sales, B.C.; Saparov, B.; McGuire, M.A.; Singh, D.J.; Parker, D.S. Ferromagnetism of $\mathrm{Fe}_{3} \mathrm{Sn}$ and alloys. Sci. Rep. 2014, 4, 7024. [CrossRef] [PubMed]

3. Giefers, H.; Nicol, M. High pressure X-ray diffraction study of all Fe-Sn intermetallic compounds and one Fe-Sn solid solution. J. Alloy. Compd. 2006, 422, 132-144. [CrossRef]

4. Gerasimov, K.B.; Boldyrev, V.V. On mechanism of new phases formation during mechanical alloying of Ag-Cu, Al-Ge and Fe-Sn systems. Mater. Res. Bull. 1996, 31, 1297-1305. [CrossRef]

5. Yelsukov, E.P.; Voronina, E.V.; Konygin, G.N.; Barinov, V.A.; Godovikov, S.K.; Dorofeev, G.A.; Zagainov, A.V. Structure and magnetic properties of $\mathrm{Fe}_{100-x} \mathrm{Sn}_{x}(3.2<x<62)$ alloys obtained by mechanical milling. J. Magn Magn. Mater. 1997, 166, 334-348.

6. Haftek, E.; Tan, M.; Barnard, J.A. Microstructure and magnetic properties of ferromagnetic Fe-Sn alloy thin films. Ultramicroscopy 1992, 47, 400-407. [CrossRef]

7. Kadyrzhanov, K.K.; Rusakov, V.S.; Korshiyev, B.O.; Turkebaev, T.E.; Vereschak, M.F. Thermally induced processes of intermetalloid phase formation in laminar systems Fe-Sn. Hyperfine Interact. 2004, 156, $623-628$. [CrossRef]

8. Kientz, M.O.; Le Caer, G.; Delcroix, P.; Fournes, L.; Fultz, B.; Matteazzi, P.; Malaman, B. ${ }^{57}$ Fe and ${ }^{117} \mathrm{Sn}$ mossbauer spectrometry studies on nanocrystallone Fe-Sn solid solutions. NanoStruct. Mater. 1995, 6, 617-620. [CrossRef] 
9. Yamamoto, T.; Nohira, T.; Hagiwara, R.; Fukunaga, A.; Sakai, S.; Nitta, K. Electrochemical behavior of Sn-Fe alloy film negative electrodes for a sodium secondary battery using inorganic ionic liquid $\mathrm{Na}[\mathrm{FSA}]-\mathrm{K}[\mathrm{FSA}]$. Electrochim. Acta 2016, 211, 234-244. [CrossRef]

10. Chisholm, C.U.; El-Sharif, A.; Kuzmann, E.; Stichleutner, S.; Homonnay, Z.; Vertes, A. Electrodeposition of Sn-Fe alloys using gluconate electrolytes and X-ray diffractometry and Mössbauer studies of the deposits. Mater. Chem. Phys. 2010, 120, 558-565. [CrossRef]

11. Hsieh, Y.H.P.; Hsieh, Y.P. Kinetics of Fe(III) reduction by ascorbic acid in aqueous solutions. J. Agric. Food Chem. 2000, 48, 1569-1573. [CrossRef] [PubMed]

12. Gustafsson, J.P. Visual MINDTEQ 3.1 2014. Available online: https://vminteq.lwr.kth.se/ (accessed on 11 April 2019).

13. Hyperquad Simulation and Speciation Software. Available online: http://www.hyperquad.co.uk/hyss.htm (accessed on 11 April 2019).

14. Andrle, C.; Jelinek, T.W. Hull-Zelle: zur Untersuchung von Galvanischen Elektrolyten, 1st ed.; Eugen G. Leuze Verlag: Bad Saulgau, Germany, 2007.

15. Guaus, E.; Torrent-Burgués, J. Voltammetric study of Sn(II) reduction on a glassy-carbon electrode from sulfate-tartrate baths. Russ. J. Electrochem. 2006, 42, 141-146. [CrossRef]

16. Lingane, J.J. Polarographic characteristics of stannous and cupric tartrate complexes and amperometric titration of tin with cupric ion in tartrate medium. J. Am. Chem. Soc. 1943, 65, 866-872. [CrossRef]

17. Smith, T.D. Chelates formed by tin(II) with citric and tartaric acids, and their interaction with certan transition-metal ions. J. Chem. Soc. 1965, 0, 2145-2150. [CrossRef]

18. Lide, D.R. CRC Handbook of Chemistry and Physics, 85th ed.; CRC Press: Boca Raton, FL, USA, 2004.

19. Akiyama, T.; Fukushima, H. Recent study on the mechanism of the electrodeposition of iron-group metal alloys. ISIJ Int. 1992, 32, 787-798. [CrossRef]

20. Lowenheim, F.A. Electroplating; McGraw-Hill: New York, NY, USA, 1978.

21. Hansal, W.E.G. Pulse Plating; Eugen G. Leuze Verlag: Bad Saulgau, Germany, 2012.

22. Pletcher, D.; Greff, R.; Peat, R.; Peter, L.M.; Robinson, J. Instrumental Methods in Electrochemistry; Woodhead Publishing Limited: Cambridge, UK, 2001.

23. Zech, N.; Podlaha, E.J.; Landolt, D. Anomalous codeposition of iron group metals: I. Experimental results anomalous codeposition of iron group metals. J. Electrochem. Soc. 1999, 146, 2886-2891. [CrossRef]

24. Dahms, H.; Croll, I.M. The anomalous codeposition of iron-nickel alloys. J. Electrochem. Soc. 1965, 112, 771-775. [CrossRef]

25. Zangari, G. Electrodeposition of alloys and compounds in the era of microelectronics and energy conversion technology. Coatings 2015, 5, 195-218. [CrossRef]

26. El-Sharif, M.; Chisholm, C.U.; Kuzmann, E.; Sziráki, L.; Stichleutner, S.; Homonnay, Z.; Süvegh, K.; Vértes, A. The structure and composition of novel electrodeposited $\mathrm{Sn}-\mathrm{Fe}$ and $\mathrm{Sn}-\mathrm{Co}-\mathrm{Fe}$ alloys from a flow circulation cell system. Hyperfine Interact. 2009, 192, 1-12. [CrossRef]

27. Kuzman, E.; Sziraki, L.; Lak, G.B.; Stichleutner, S.; Havancsak, K.; Süvegh, K.; El-Sharif, M.; Chisholm, C.U.; Homonnay, Z.; Vértes, A. Mössbauer, X-ray diffraction, and microscopy investigations of novel electrodeposited amorphous alloys. AIP Conf. Proc. 2012, 1489, 3-12.

(C) 2019 by the authors. Licensee MDPI, Basel, Switzerland. This article is an open access article distributed under the terms and conditions of the Creative Commons Attribution (CC BY) license (http://creativecommons.org/licenses/by/4.0/). 